\title{
Interactive comment on "Parameterized reactivity of hydroxy radical, ozone, nitrate radical and atmospheric oxidation capacity during summer at a suburban site between Beijing and Tianjin" by Yuan Yang et al.
}

\section{Yuan Yang et al.}

yonghong.wang@helsinki.fi

Received and published: 27 April 2020

The comment was uploaded in the form of a supplement:

https://www.atmos-chem-phys-discuss.net/acp-2019-788/acp-2019-788-AC3-

supplement.pdf 